\title{
A Comparative Study between the Postoperative Complications of Stripping Esophagectomy and Classic (Orringer's Technique) Esophagectomy
}

\author{
Mojtaba Ahmadinejad, MD ${ }^{1}$ Mozaffar Hashemi, MD ${ }^{2}$ Abbas Tabatabai, MD² \\ ${ }^{1}$ Department of General Surgery, Faculty of Medicine, Úlborz \\ University of Medical Sciences, Karaj, Iran \\ 2 Department of General Surgery, Faculty of Medicine, Isfahan \\ University of Medical Sciences, Isfahan, Iran \\ Address for correspondence Mozaffar Hashemi, MD, Isfahan \\ University of Medical Sciences, Isfahan, Iran \\ (e-mail: md.mozaffarhashemi@gmail.com).
}

Surg J (NY) 2022;8:e34-e40.

\author{
Abstract \\ Keywords \\ - stripping \\ - nasogastric tube \\ - transhiatal \\ esophagectomy \\ - Orringer \\ - stripping \\ - esophageal \\ carcinoma
}

Recent studies have suggested that morbidity and mortality rate of transhiatal esophagectomy is comparable to that of thoracotomy, calling the need for the modifications in the surgical procedures. Our methodology includes stripping of esophagus by nasogastric tube to reduce the manipulation of thoracic cavity and associated complications. We also present the comparison between the stripping and classic (Orringer's technique) esophagectomy.

Patients presenting esophageal carcinoma from 2015 to 2017 were the target of this study. Patients undergoing esophagectomy were randomized to have classic or stripping esophagectomy. Operating time, manipulation time, blood losses during the surgery, duration of hospitalization, volume intake, hypotension time, arrhythmia, and transfusion were the recorded parameters. Complications, such as anastomotic leak, cardiac effects, and morbidity, were also studied. Seventy patients were referred for transhiatal esophagectomy for esophageal carcinoma at the Al Zahra Hospital. Mean ages of patients in the stripping and Orringer group were $64.00 \pm 10.57$ and $57.42 \pm 12.20$ years, respectively. Manipulation time, operating time, blood loss during the surgery, and transfusion were statistically significant variables between the two groups. Although volume intake and duration of hospitalization were not significantly different parameters, however, betterment in the outcomes was evident. Substantial decrease in overall complications via stripping method was obtained, hence can be suggested as an effective alternative, to remove the need of thoracotomy, for transhiatal esophagectomy.
Esophageal cancer contributes as the eight most frequent cancers, reported globally. Histologically, it can be either seen as squamous cell carcinoma, dominant one, or adenocarcinoma, each associated with differential epidemiology risks and consequences. It is mostly common in males and Caucasians, while adenocarcinoma is chiefly reported in Chinese

received

January 4, 2020 accepted after revision August 19, 2021
DOI https://doi.org/ $10.1055 / \mathrm{s}-0041-1736666$ ISSN 2378-5128. population. Factors that primarily contribute to the incidence of this cancer include obesity, bacterial and viral infections, smoking, alcohol, gastroesophageal reflux disease, Barrett's esophagus, and side effects of certain drugs. ${ }^{1}$

Depending on the severity of the disease, several treatment options are available. Premalignant treatment is
(C) 2022. The Author(s).

This is an open access article published by Thieme under the terms of the Creative Commons Attribution License, permitting unrestricted use, distribution, and reproduction so long as the original work is properly cited. (https://creativecommons.org/licenses/by/4.0/)

Thieme Medical Publishers, Inc., 333 Seventh Avenue, 18th Floor, New York, NY 10001, USA 
successfully provided using mucosal resection and radiofrequency ablation, ${ }^{2}$ whereas localized cancer is operated by esophagectomy. ${ }^{3}$

Several surgical options withstand in case of benign and malignant esophageal lesions. ${ }^{4}$ Benign or malignant condition of the lesion, the extent of the lesion, location of the tumor, and the presence of complications are some of the factors which determine the type of surgical procedure required, ${ }^{5}$ nonetheless, esophagectomy is usually recommended for the patients with benign conditions. ${ }^{6}$ These surgical procedures include transthoracic esophageal resection by either right or left thoracotomy and transhiatal esophageal resection (Orringer's esophagectomy) without thoracotomy. Nonetheless, low-to-no difference in survival rate has been noted between either of these procedures. ${ }^{7}$ Transhiatal method includes removal of greater number of metastasized lymph nodes, which is operated for adenocarcinoma-type esophageal cancer. ${ }^{8}$ Recent studies suggest transhiatal esophagectomy has morbidity and mortality rates comparable to thoracotomy esophagectomy which cause this surgical procedure as an alternative to traditional transthoracic esophagectomy. ${ }^{9-11}$ Complications such as hemorrhage (due to the damage of the azygos vein, aortic esophageal artery, or thoracic aorta), anastomotic leak, mediastinitis, pulmonary complications, arrhythmia, and anastomotic stricture may occur during or after the procedure with esophageal resection and reconstruction. ${ }^{12-14}$ Dissection of the esophagus from the posterior mediastinum can be hemodynamically challenging. ${ }^{15}$ Less manipulation and reducing operative-chest involvement during procedure can, however, reduce morbidity and mortality in this surgical procedure.

This study provides an alternative technique for transhiatal esophagectomy and provides comparative analysis.

\section{Materials and Methods}

\section{Subject Recruitment}

Patients presenting esophageal carcinoma (benign) were enrolled in this study. Patients were randomly assigned to undergo classic transhiatal (Orringer's technique) or stripping esophagectomy (eversion esophagectomy). G Power software is used to estimate sample size (Faul et $\mathrm{al}^{16}$ ).

\section{Operation Technique}

A nasogastric tube was fixed in stomach before operation. Abdominal and cervical neck incision was performed in transhiatal esophagectomy without opening thoracic cavity. To it, stomach was entirely immobilized for the procedure. Lymph nodes surrounding the distal part of the esophagus, the gastric cardia, omentum, and the left gastric artery were removed. Blunt method was exploited to cut the intrathoracic part of the esophagus, distancing it from adjacent thoracic structures.

To accomplish this procedure, the surgeon opened the diaphragmatic hiatus and mobilized the esophagus by dissecting up into the thoracic cavity. The cervical component of the operation involved opening the neck followed by the lateral retraction of sternocleidomastoid.
The part of the esophagus in the neck was isolated and dissected away from the flanking trachea. In our procedure the esophagus was then partially dissected in the neck. Nasogastric tube fixation was made free from the nose and brought out of the field approximately $30 \mathrm{~cm}$ then esophagus was tied to the nasogastric tube from the distal part. Partial incision of neck esophagus was made complete, and from a small incision in the esophagogastric junction, the tip of the nasogastric tube was pulled ( - Fig. $\mathbf{1}$ ).

After division of the upper part of the stomach, along with the esophagus, it was sent for histological examination to pathology laboratory. To establish gastrointestinal continuity, remaining part of the stomach was reconnected with the tube, passing it through the posterior mediastinum while connecting the cervical region of the esophagus to the stomach passing the tube up through the posterior mediastinum and by manual stitches using 3-0 Vicryl. All the operations were performed by the same surgeon.

The time of the operation, manipulation time, blood loss during the surgery, duration of hospitalization, volume intake, hypotension, and transfusion were noted. Other complications, such as anastomotic leak, cardiac effects, and mortality, were also under consideration. After the surgery, patients were assessed for anastomotic leakage by a meglumine diatrizoate (Gastrografin) contrast study performed on day 7, postoperatively. Anastomotic leakage was diagnosed based on clinical and radiological confirmations.

Patients were followed-up every 2 weeks for 2 months and monthly thereafter for 1 year, then at 3-monthly intervals after their discharge from the hospital. If symptoms of dysphagia returned, endoscopic and barium swallow examinations were performed. Diagnosis regarding benign anastomotic narrowing was done during endoscopy; passage of a $10-\mathrm{mm}$ diameter flexible endoscope. Histological evidences showed malignant narrowing.

For our analysis, development of the benign stricture, patients' death in the hospital, anastomotic leakage, or recurrence of malignancy were excluded. G Power software is used to estimate sample size. ${ }^{16}$

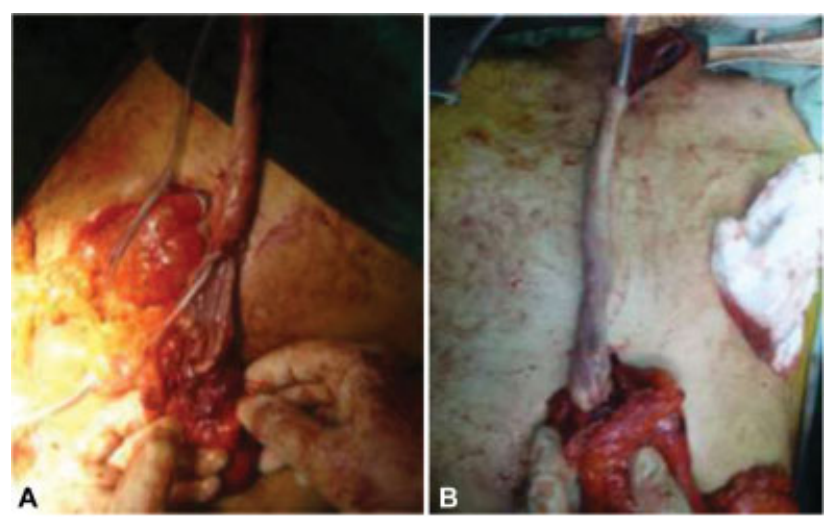

Fig. 1 The esophagus view (A) before and (B) after stripping. 
$\mathrm{t}$ tests - Means: Difference between two independent means (two groups)

Tail(s) $=$ Two, Total sample size $=70$, Allocation ratio $\mathrm{N} 2 / \mathrm{N} 1=1, \alpha$ err prob $=0.05$

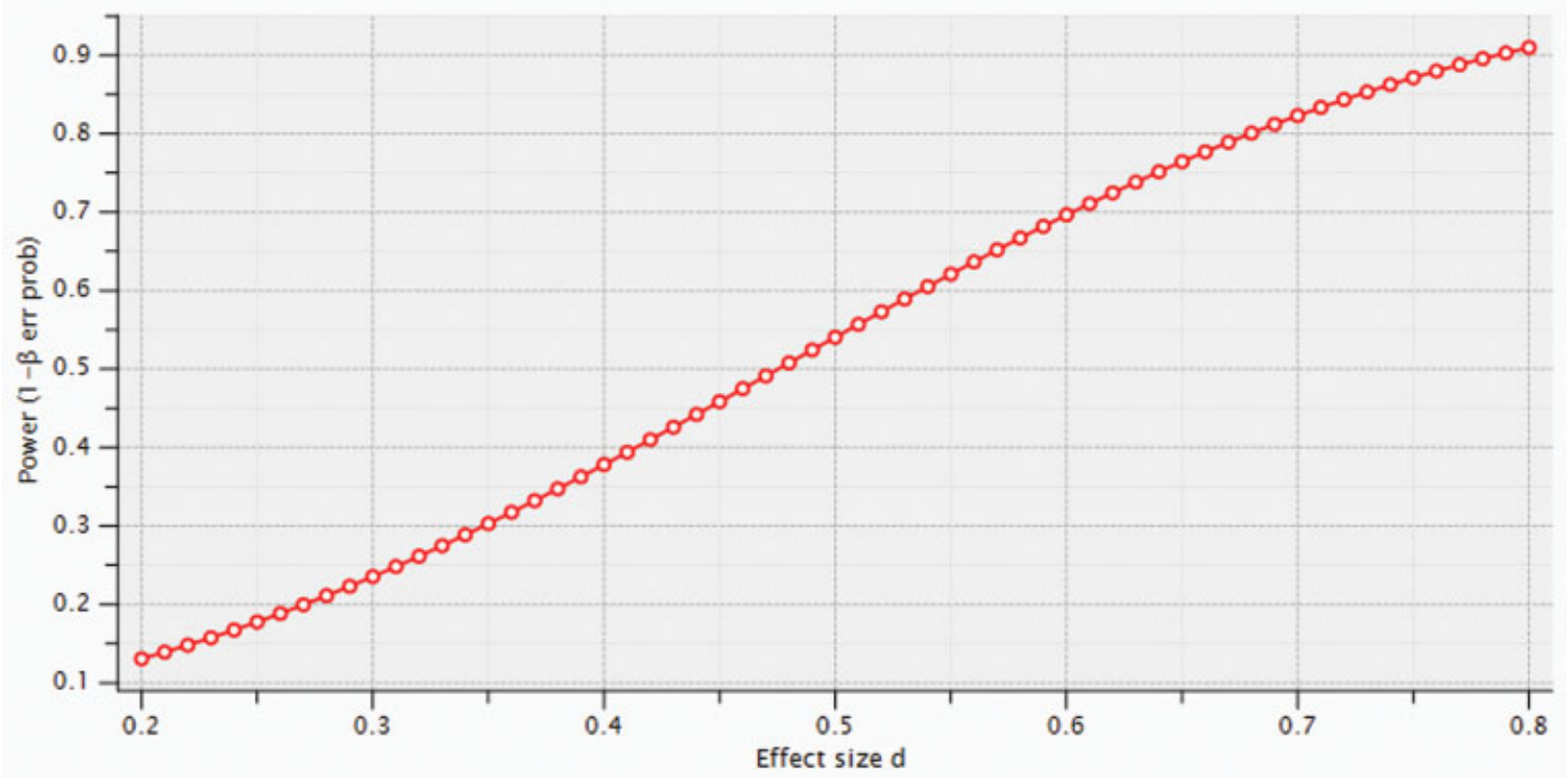

Fig. 2 Achieved power given different effect sizes at significant level $(\alpha=0.05)$ and sample size 70 (35 per each group).

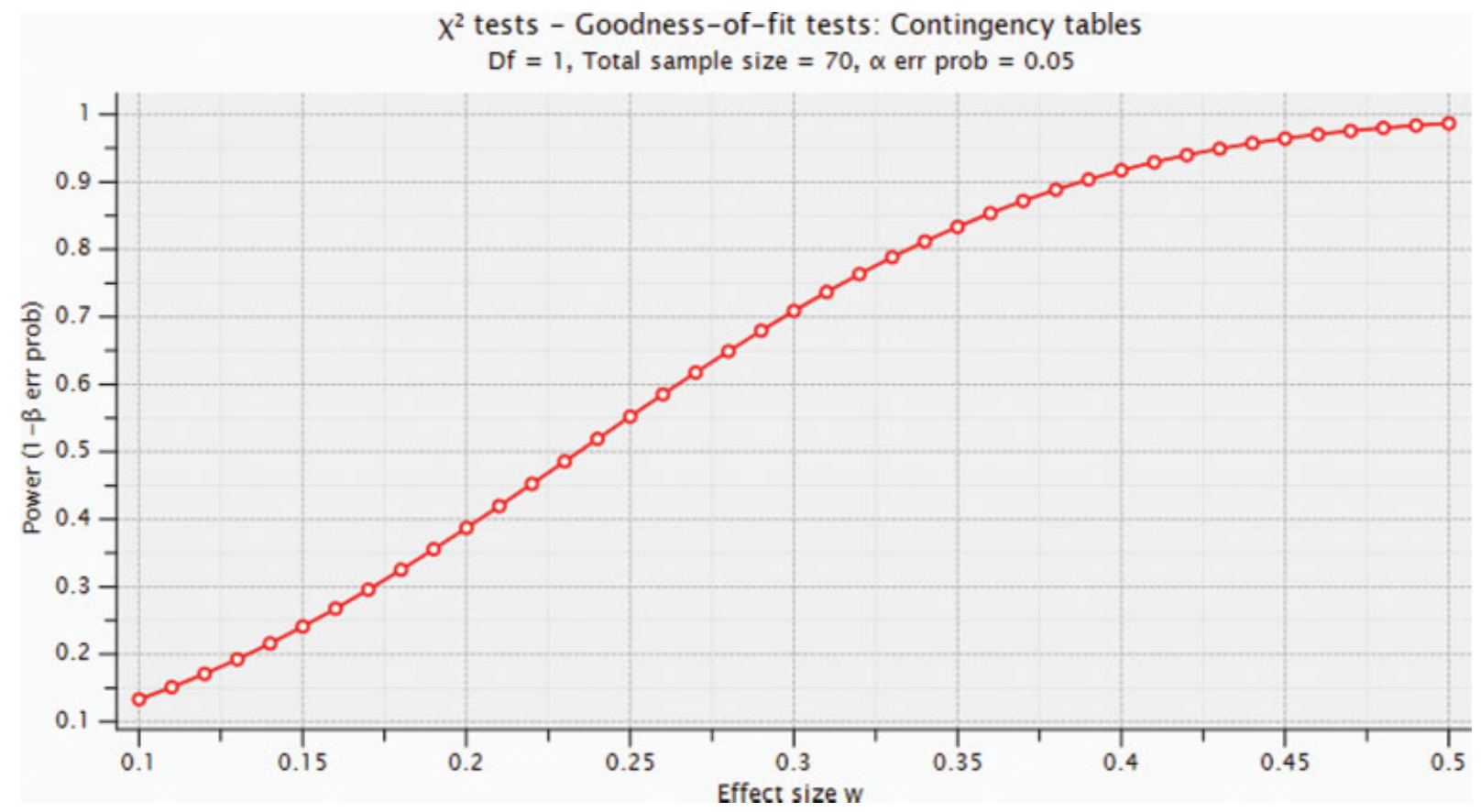

Fig. 3 Achieved power given different effect sizes at significant level $(\alpha=0.05)$ and total sample size 70 (35 per each group).

\section{Power Analysis}

We used independent $t$-test and chi-square test to compare quantitative and qualitative complications between stripping and classic esophagectomy, respectively.

\section{Power Analysis for Independent $t$-Test}

As we can see in -Fig. 2, $t$-test can find moderate to large differences $(0.6<d<0.8)$ with a reasonable power $(1-\beta>0.7){ }^{17}$

\section{Power Analysis for Chi-Square Test}

As we can see in - Fig. 3, chi-square test can find moderate to large differences $(0.3<d<0.5)$ with a reasonable power $(1-\beta>0.7)$.

\section{Statistical Analysis}

Statistical analysis among the two groups was conducted using Student's t-test and the chi-square test. A $p$-value of 
Table 1 Demographic data, operative, and postoperative data comparison between two groups

\begin{tabular}{|c|c|c|c|}
\hline $\begin{array}{l}\text { Age }(\mathrm{y}) \\
(\text { mean } \pm \text { SEM) }\end{array}$ & $\begin{array}{l}\text { Stripping } \\
(n=35) \\
64.00 \pm 10.57\end{array}$ & $\begin{array}{l}\text { Orringer } \\
(n=35) \\
57.42 \pm 12.20\end{array}$ & $p$ \\
\hline \multicolumn{4}{|l|}{$\operatorname{Sex}(\%)$} \\
\hline Male & $25(71.5)$ & $20(57.1)$ & 0.318 \\
\hline Female & $10(28.6)$ & $15(42.9)$ & \\
\hline Manipulation time $(\min \pm \mathrm{SEM})$ & $5.42 \pm 1.53$ & $7.74 \pm 2.27$ & 0.00 \\
\hline Operating time ( $\min \pm \mathrm{SEM})$ & $99.71 \pm 20.61$ & $112.14 \pm 12.14$ & 0.003 \\
\hline Blood loss $(\mathrm{mL} \pm$ SEM) & $442.85 \pm 109.98$ & $530.00 \pm 121.99$ & 0.003 \\
\hline Volume intake $(\mathrm{L} \pm \mathrm{SEM})$ & $1.43 \pm 0.22$ & $1.60 \pm 0.35$ & 0.85 \\
\hline Duration of hospitalization & $10.51 \pm 3.99$ & $12.05 \pm 5.83$ & 0.20 \\
\hline \multicolumn{4}{|l|}{ Transfusion (\%) } \\
\hline Yes & 0 & $6(17.1)$ & 0.025 \\
\hline No & 35 & $29(81.9)$ & \\
\hline \multicolumn{4}{|l|}{ Hypotension during surgery } \\
\hline Yes & $15(42.9)$ & $22(62.9)$ & 0.15 \\
\hline No & $20(57.1)$ & $13(37.1)$ & \\
\hline Reoperation & $6(17.1)$ & $10(28.6)$ & 0.39 \\
\hline \multicolumn{4}{|l|}{ Anastomotic leaks (\%) } \\
\hline Yes & $7(20)$ & $5(14.3)$ & \\
\hline No & $28(80)$ & $30(85.7)$ & 0.75 \\
\hline \multicolumn{4}{|l|}{ Anastomotic stricture(\%) } \\
\hline Yes & $4(11.4)$ & $4(11.4)$ & 1.00 \\
\hline No & $31(88.6)$ & $31(88.6)$ & \\
\hline \multicolumn{4}{|l|}{ Cardiac complication (\%) } \\
\hline Yes & $13(37)$ & $16(45)$ & 0.62 \\
\hline No & $22(63)$ & $19(55)$ & \\
\hline \multicolumn{4}{|l|}{ 30-day mortality (\%) } \\
\hline Yes & $3(8.57)$ & $3(8.57)$ & 1.00 \\
\hline No & $32(91.43)$ & $32(91.43)$ & \\
\hline
\end{tabular}

Abbreviation: SEM, standard error of the mean.

0.05 was regarded as significant. Data were analyzed using SPSS 15.0 (SPSS Inc., Chicago, IL) software.

\section{Ethical Consideration}

Study protocols were approved by the Ethical Review Board of Isfahan University of Medical Sciences. Written informed consent was endorsed either by all the individual participants of the study or their parents/guardians.

\section{Result}

In the period of our study, altogether 70 patients presenting esophageal carcinoma were suggested for transhiatal esophagectomy at the Al Zahra Hospital. Mean ages of the participating patients in the stripping and Orringer groups were $64.00 \pm 10.57$ and $57.42 \pm 12.20$ years, respectively. Manipulation and operating time, blood loss during the surgery, and transfusion were the statistically significant variables among the two groups ( - Table $\mathbf{1}$ ). Anastomotic leakage was reported in 7 patients in the stripping group and in 5 patients in the Orringer group, which was not statistically significant, $p=0.75$. Additionally, anastomotic stricture in these two groups was reported in 4 patients, respectively, $p=1.0$ (-Table 1).

Although volume intake and duration of hospitalization were not significant, they implicated betterment in the outcomes. Note that $64.5 \%$ of patients with Orringer striping surgery suffered from hypotension, $11.5 \%$ of patients needed transfusion during surgery (3.3\% in the first group and $19.4 \%$ in the second group). Of 31 patients with arrhythmia, 9 patients (29\%) had premature atrial contraction (PAC) (1), 5 patients (16.1\%) sinus bradycardia, and 16 patients (54.9\%) presented PAC-premature ventricular contraction (PVC) (2). Mean time of manipulation in the three types of arrhythmia was not significantly different $(p=0.36)$. Five patients with preoperative PAC-related arrhythmias, continued to have 
Table 2 Relationship between arrhythmias and hypotension with qualitative variables

\begin{tabular}{|l|l|l|l|l|l|l|}
\hline \multirow{2}{*}{ Variable hypotonia arrhythmia } & \multicolumn{2}{|l|}{ Hypotonia } & \multirow{2}{*}{$p$-Value } & \multicolumn{2}{l|}{ Arrhythmia } & \multirow{2}{*}{-Value } \\
\cline { 2 - 3 } & No & Yes & & No & Yes & \\
\hline Cigarette & $29.6 \%$ & $29.4 \%$ & 0.98 & $32.3 \%$ & $26.7 \%$ & 0.63 \\
\hline Classical stripping method & $53.4 \%$ & $46.7 \%$ & 0.16 & $66.7 \%$ & $33.3 \%$ & 0.015 \\
& $35.5 \%$ & $64.5 \%$ & & $35.5 \%$ & $64.5 \%$ & \\
\hline Transfusion & $2.7 \%$ & $17.6 \%$ & 0.12 & $10 \%$ & $23.3 \%$ & 0.005 \\
\hline Hypotension during manipulation & & & & $45.2 \%$ & $66.7 \%$ & 0.09 \\
\hline Complications & $33.3 \%$ & $58.8 \%$ & 0.04 & $45.2 \%$ & $50 \%$ & 0.7 \\
\hline Mortality & $7.7 \%$ & $11.8 \%$ & 0.68 & $10 \%$ & $10 \%$ & 1 \\
\hline SCC adenocarcinoma pathology & $42.1 \%$ & $57.9 \%$ & 0.52 & $48.4 \%$ & $80 \%$ & 0.02 \\
\hline Arrhythmia before manipulation & $45.5 \%$ & $59.4 \%$ & & $51.6 \%$ & $20 \%$ & \\
\hline Hypotension before manipulation & $11.1 \%$ & $5.9 \%$ & $68 \%$ & $0 \%$ & $16.7 \%$ & 0.02 \\
\hline Weight loss 20\% & $7.4 \%$ & $8.8 \%$ & 1 & $3.2 \%$ & $13.3 \%$ & $19 \%$ \\
\hline Reoperation & $22.2 \%$ & $33.3 \%$ & $34 \%$ & $29 \%$ & $27.6 \%$ & $9 \%$ \\
\hline Arrhythmia during manipulation & $14.8 \%$ & $28.2 \%$ & 0.04 & $29 \%$ & $26.7 \%$ & $83 \%$ \\
\hline Albumin $<3.5$ & $37 \%$ & $58.8 \%$ & $0.09 \%$ & & & \\
\hline FEV1>2 & $37 \%$ & $66.7 \%$ & $68 \%$ & $61.3 \%$ & $67.9 \%$ & $59 \%$ \\
\hline
\end{tabular}

Abbreviations: FEV1, forced expiratory volume in 1 second; SCC, squamous cell carcinoma.

Table 3 Arrhythmia and hypotension relation with quantitative variables

\begin{tabular}{|l|l|l|l|l|l|l|}
\hline \multirow{2}{*}{$\begin{array}{l}\text { Arrhythmia and } \\
\text { variable hypotension }\end{array}$} & Arrhythmia & \multirow{2}{*}{-Value } & \multicolumn{2}{l|}{ Hypotension } & \multirow{2}{*}{$p$-Value } \\
\cline { 2 - 2 } \cline { 5 - 6 } & Yes & No & & Yes & No & \\
\hline FEV1 & $2.02 \pm 0.45$ & $2.06 \pm 0.39$ & 0.78 & $1.93 \pm 0.28$ & $2.17 \pm 0.44$ & 0.03 \\
\hline Manipulation time & $6.9 \pm 2.29$ & $6.67 \pm 2.5$ & 0.71 & $7.64 \pm 2.42$ & $5.7 \pm 1.87$ & 0.001 \\
\hline Operating time & $110.33 \pm 21.65$ & $102.41 \pm 12.44$ & 0.08 & $105.73 \pm 13.3$ & $107.03 \pm 22.6$ & 0.78 \\
\hline Blood loss & $541.66 \pm 18.198$ & $472.58 \pm 104.75$ & 0.07 & $541.17 \pm 172.53$ & $462.96 \pm 105.24$ & 0.04 \\
\hline Systolic blood pressure & $12.66 \pm 1.09$ & $12.51 \pm 0.76$ & 0.53 & $12.91 \pm 0.86$ & $12.18 \pm 0.87$ & 0.002 \\
\hline Diastolic blood pressure & $8.36 \pm 0.76$ & $8.29 \pm 0.82$ & 0.7 & $8.58 \pm 0.65$ & $8 \pm 0.83$ & 0.03 \\
\hline Volume intake & $1.69 \pm 0.42$ & $1.47 \pm 0.19$ & 0.01 & $1.65 \pm 0.38$ & $1.49 \pm 0.27$ & 0.06 \\
\hline Duration of hospitalization & $13.7 \pm 10.73$ & $11.3 \pm 3.97$ & 0.25 & $13.88 \pm 9.69$ & $10.69 \pm 5.07$ & 0.13 \\
\hline
\end{tabular}

Abbreviation: FEV1, forced expiratory volume in 1 second.

them perioperatively. The most common type of arrhythmias in classic striping surgery was bradycardia (40\%), whereas in classical surgery it was PAC-PVC $(66.2 \%)(p=0.03)$. The mean hypotension time was $4.28 \pm 1.06$ minutes ( $\max 70$ and at least 30 minutes), in the first group it was $3.5 \pm 0.7$ minutes and in the second group $4.68 \pm 1$ minutes. After surgery, $10.16 \%$ of patients had arrhythmia in first 24 hours, $47.5 \%$ of patients had complications and $8.57 \%$ of the patients died within the first 30 days in both the groups.

In the acquired pathology, it was found that $62.3 \%$ patients with squamous cell carcinoma, $36.1 \%$ had adenocarcinoma, whereas $1.6 \%$ of those were inflicted with squamous adenocarcinoma. To examine the relationship between existing variables with the development of arrhythmias, the following items were discerned statistically significant: need for transfusion, the type of pathology of the tumor, the presence of arrhythmia before the surgery, forced expiratory volume in 1 second (FEV1) of less than $2 \mathrm{~L}$, and the amount of fluid received ( $\boldsymbol{-}$ Tables $\mathbf{2}$ and $\mathbf{3}$ ).

In relation to the existing variables with hypotension, duration of manipulation, amount of bleeding, systolic and diastolic blood pressure before manipulation, and FEV1 less than $2 \mathrm{~L}$ were correlated. In patients with arrhythmia, the complications and postoperative mortality were not significantly different from that of the control group, but in patients with hypotension, the overall complications and need for reoperation were significantly more than the control group. In all treated patients, the study was considered for coagulation disorder where international normalized ratio was normal in both the groups. No patients demonstrated 
extensive bleeding perioperatively, therefore there was no need for a keratectomy. The relationship between the variables with the arrhythmia surgery, duration of mediastinal surgery and operation, duration of hypotension during mediastinal surgery, and blood transfusion rates were significantly lower in the striping method.

\section{Discussion}

Transhiatal esophagectomy is recommended for adenocarcinoma-type esophageal cancer at lower chest and cardia. However, several complications are reported in conventional method. Techniques to overcome these adverse effects include minimally invasive esophagectomy, anti-inflammatory drugs, fluid management during the surgery, and postoperative nasogastric decompression. ${ }^{18}$ In a recent case report, esophagus was stripped due to the adhesion in the thoracic cavity in patient with esophageal carcinoma of squamous cell type. ${ }^{19}$

Rajan et $\mathrm{al}^{20}$ described the use of vein stripper to extract esophagus, eversion stripping, the esophagus, at the same time excising the tumor from the larynx, pharynx, and esophagus, with a significant reduction in morbidity compared with the Akiyama et al study. ${ }^{21}$

We have successfully exploited nasogastric tube for extraction of the esophagus with a comparable reduction in morbidity. Further optimizing of the reconstructive procedure is likely to provide reduction in mortality and morbidity rates, shorter hospital stay, and rapid return to successful feeding. ${ }^{22,23}$ A study has been reported stating insecurity of nasogastric tube, particularly, for proximal esophagus stripping hence requiring vein stripping for the purpose. ${ }^{24}$

Postoperative complications are very important factor in choosing surgical method. In the present study, cardiac complications were one of the common complications of procedures (37\%) and is comparable with previous reports. ${ }^{25}$

In a recent survey by Orringer et $\mathrm{al}^{26}$ it was shown the mean blood loss was respectively $677 \mathrm{~mL}$ in surgeries during 1976 to 1998 and $368 \mathrm{~mL}$ during 1998 to 2006. In our study, the mean blood loss was $442.85 \pm 109 / 98 \mathrm{~mL}$ which is significantly lower than comparable studies.

The overall anastomotic leak rate after cervical esophagogastric anastomosis has been reported $12 \%$ by Orringer et al, although in this study by stripping method anastomotic leak was $20 \%$. The anastomotic stricture was same in the two groups of our study (11.4\%); however, it is comparable to $42 \%$ that has been reported by Honkoop et al. ${ }^{27}$

Blunt finger dissection has been reported to produce critical complications and morbidity. ${ }^{28}$ In previous studies, 30 days mortality was from 5 to 11 to $15 \%,{ }^{29,30}$ whereas $8.57 \%$ in the present study. Decreased mortality rate in the present study probably reflects less manipulation and avoiding operative chest complications during our procedure.

Despite overall decrease in postoperative complication achieved by nasogastric stripping, comparison with other minimally invasive techniques via laparoscopy or thoraco- scopy, Ivor Lewis and Mckeown esophagectomy, can provide a decisive answer. ${ }^{31}$ Further reduction in complications and mortality rate are likely to be achieved by integrating these methods. $^{32-34}$

Ethical Approval and Consent to Participate

All procedures performed in this study involving human participants were in accordance with the ethical standards of the institutional and/or national research committee and with the 1964 Helsinki Declaration and its later amendments or comparable ethical standards.

\section{Consent to Participate}

From the under 16 years old was given by a parent or legal guardian.

Consent for Publication

Not applicable.

Availability of Data and Material

Data sharing is not applicable to this article as no data sets were generated or analyzed during the current study.

\section{Authors' Contributions}

Dr. Mojtaba Ahmadinejad: conceptualized and designed the study, drafted the initial manuscript, and reviewed and revised the manuscript.

Dr. Mozaffar Hashemi: Designed the data collection instruments, collected data, performed the initial analyses, and reviewed and revised the manuscript.

Dr. Abbas Tabatabai: Coordinated and supervised data collection, and critically reviewed the manuscript for important intellectual content.

\section{Funding}

No funding was secured for this study.

\section{Conflict of Interest}

The authors deny any conflict of interest in any terms or by any means during the study. All the fees provided by research center fund and deployed accordingly.

\section{Acknowledgments}

None.

\section{References}

1 Abbas G, Krasna M. Overview of esophageal cancer. Ann Cardiothorac Surg 2017;6(02):131-136

2 Haidry RJ, Butt MA, Dunn JM, et al; UK RFA Registry. Improvement over time in outcomes for patients undergoing endoscopic therapy for Barrett's oesophagus-related neoplasia: 6-year experience from the first 500 patients treated in the UK patient registry. Gut 2015;64(08):1192-1199

3 Kim SH, Lee KS, Shim YM, Kim K, Yang PS, Kim TS. Esophageal resection: indications, techniques, and radiologic assessment. Radiographics 2001;21(05):1119-1137, discussion 1138-1140

4 Orringer MB, Marshall B, Stirling MC. Transhiatal esophagectomy for benign and malignant disease. J Thorac Cardiovasc Surg 1993; 105(02):265-276, discussion 276-277 
5 Orringer MB, Marshall B, Iannettoni MD. Transhiatal esophagectomy: clinical experience and refinements. Ann Surg 1999;230 (03):392-400, discussion 400-403

6 D’Amico TA. Mckeown esophagogastrectomy. J Thorac Dis 2014;6 (Suppl 3):S322-S324

7 Barreto JC, Posner MC. Transhiatal versus transthoracic esophagectomy for esophageal cancer. World J Gastroenterol 2010;16 (30):3804-3810

8 Łochowski M, Łochowska B, Kozak J. Transthoracic versus transhiatal esophagectomy - influence on patient survival. Prz Gastroenterol 2017;12(02):118-121

9 Scripcariu V, Diaconu C, Stoian M, Dragomir C. Transhiatal esophagectomy for treatment of benign and malignant esophageal diseases [in Romanian]. Rev Med Chir Soc Med Nat Iasi 2004; 108(02):390-396

10 Lin J, Iannettoni MD. Transhiatal esophagectomy. Surg Clin North Am 2005;85(03):593-610

11 Orringer MB, Marshall B, Iannettoni MD. Transhiatal esophagectomy for treatment of benign and malignant esophageal disease. World J Surg 2001;25(02):196-203

12 Hankins JR, Attar S, Coughlin TR Jr, et al. Carcinoma of the esophagus: a comparison of the results of transhiatal versus transthoracic resection. Ann Thorac Surg 1989;47(05):700-705

13 Uravić M, Petrosić N, Depolo A, et al. Transhiatal esophagectomy for carcinoma of the esophagus-our ten years experience [in German]. Zentralbl Chir 2002;127(11):956-959

14 Rao YG, Pal S, Pande GK, Sahni P, Chattopadhyay TK. Transhiatal esophagectomy for benign and malignant conditions. Am J Surg 2002;184(02):136-142

15 Malhotra SK, Kaur RP, Gupta NM, Grover A, Ramprabu K, Nakra D. Incidence and types of arrhythmias after mediastinal manipulation during transhiatal esophagectomy. Ann Thorac Surg 2006;82 (01):298-302

16 Faul F, Erdfelder E, Lang A-G, Buchner A. G*Power 3: a flexible statistical power analysis program for the social, behavioral, and biomedical sciences. Behav Res Methods 2007;39(02):175-191

17 Cohen J. Statistical Power Analysis for the Behavioral Sciences. New York, NY: Academic Press; 2013

18 Weijs TJ, Ruurda JP, Nieuwenhuijzen GA, van Hillegersberg R, Luyer MD. Strategies to reduce pulmonary complications after esophagectomy. World J Gastroenterol 2013;19(39):6509-6514

19 Kimura M, Nagasaki T, Kuwabara Y, et al. Eversion stripping of the esophagus with intraesophageal insufflation-a case report. Int J Surg Case Rep 2017;36:86-89

20 Rajan R, Rajan R, Rajan N, Pai US. Gastric pull-up by eversion stripping of oesophagus. J Laryngol Otol 1993;107(11):1021-1024

21 Akiyama H, Hiyama M, Miyazono $\mathrm{H}$. Total esophageal reconstruction after extraction of the esophagus. Ann Surg 1975;182(05): $547-552$
22 Cole CJ, Garden AS, Frankenthaler RA, et al. Postoperative radiation of free jejunal autografts in patients with advanced cancer of the head and neck. Cancer 1995;75(09):2356-2360

23 Böttger T, Bumb P, Dutkowski P, Schlick T, Junginger T. Carcinoma of the hypopharynx and the cervical oesophagus: a surgical challenge. Eur J Surg 1999;165(10):940-946

24 Jobe BA, Kim CY, Minjarez RC, O’Rourke R, Chang EY, Hunter JG. Simplifying minimally invasive transhiatal esophagectomy with the inversion approach: lessons learned from the first 20 cases. Arch Surg 2006;141(09):857-865, discussion 865-866

25 Chu K-M, Law SY, Fok M, Wong J. A prospective randomized comparison of transhiatal and transthoracic resection for lower-third esophageal carcinoma. Am J Surg 1997;174(03): 320-324

26 Orringer MB, Marshall B, Chang AC, Lee J, Pickens A, Lau CL. Two thousand transhiatal esophagectomies: changing trends, lessons learned. Ann Surg 2007;246(03):363-372, discussion 372-374

27 Honkoop P, Siersema PD, Tilanus HW, Stassen LP, Hop WC, van Blankenstein M. Benign anastomotic strictures after transhiatal esophagectomy and cervical esophagogastrostomy: risk factors and management. J Thorac Cardiovasc Surg 1996;111(06):1141-1146, discussion 1147-1148

28 Atiyah RA, Shindo M, Sisson GA Sr. Mediastinal dissection and gastric pull-up. Otolaryngol Clin North Am 1991;24(06): 1287-1294

29 Hartley BE, Bottrill ID, Howard DJ. A third decade's experience with the gastric pull-up operation for hypopharyngeal carcinoma: changing patterns of use. J Laryngol Otol 1999;113(03): 241-243

30 Rezaie J, Peyvandi H, Hallaj-Mofrad H, Shakiba AKB. Gastric pullup reconstruction for pharyngolaryngoesophagectomy in head and neck cancer and cervical esophageal squamous cell carcinoma. Acta Med Iran 2007; $\cdots:$ :473-476

31 Wang W, Liu F, Hu T, Wang C. Matched-pair comparisons of minimally invasive esophagectomy versus open esophagectomy for resectable esophageal cancer: a systematic review and metaanalysis protocol. Medicine (Baltimore) 2018;97(28):e11447

32 van Workum F, Berkelmans GH, Klarenbeek BR, Nieuwenhuijzen GAP, Luyer MDP, Rosman C. McKeown or Ivor Lewis totally minimally invasive esophagectomy for cancer of the esophagus and gastroesophageal junction: systematic review and metaanalysis. J Thorac Dis 2017;9(Suppl 8):S826-S833

33 van Workum F, Slaman AE, van Berge Henegouwen MI, et al. Propensity score-matched analysis comparing minimally invasive Ivor Lewis versus minimally invasive Mckeown esophagectomy. Ann Surg 2020;271(01):128-133

$34 \mathrm{Mu} J-W$, Gao S-G, Xue Q et al. Updated experiences with minimally invasive McKeown esophagectomy for esophageal cancer. World J Gastroenterol 2015;21(45):12873-12881 